\title{
The Role of Sticking Efficiencies in Hydrogen Gas Adsorption on Metal Organic Frameworks
}

\author{
${ }^{\mathrm{a}}$ Esosa Iriowen, ${ }^{\mathrm{b}}$ Samuel Orefuwa, ${ }^{\mathrm{c} *}$ Andrew Goudy \\ Delaware State University, Department of Chemistry, 1200 N Dupont Highway \\ Dover. DE 19901 USA \\ Email: ${ }^{a} x$ xe.iriowen@yahoo.com, ${ }^{b}$ sammybid@yahoo.com, ${ }^{c}$ agoudy@desu.edu \\ *Corresponding author, Tel: 302-857-6534, Fax: 302-857-6539
}

\begin{abstract}
In this study, the adsorption of hydrogen gas on 17 MOFs was compared. The majority of the MOFs contained carboxylate type linkers and metal centers such as $\mathrm{Cu}$ and $\mathrm{Zn}$. A new parameter denoted sticking efficiency was used to compare the adsorption behaviors of the 17 MOFs. Results showed that a better correlation exists between sticking efficiency and hydrogen adsorption capacity than between surface area and adsorption capacity. However, when only MOFs containing similar types of linkers were included in the comparison, the surface area correlated somewhat better with adsorption capacity than did sticking efficiency. Since a direct correlation was also found between the sticking efficiency and the adsorption enthalpy it appears that sticking efficiency is a measure of the binding energies of the MOFs.
\end{abstract}

Keywords: Metal Organic Frameworks; Sticking efficiency; Hydrogen adsorption isotherm

\subsection{Introduction}

There is great interest in materials that can adsorb and store hydrogen for a variety of practical applications. Metal organic frameworks (MOFs) have attracted considerable attention because many of them possess large surface areas with the potential to adsorb significant amounts of hydrogen gas [1-3]. MOFs are constructed of metal centers that are linked together through organic ligands, generally referred to as linkers. These MOFs may contain a variety of ligands but one of the most studied classes of MOFs has been those containing carboxylate ligands $[4,5]$. Some of the carboxylate ligands include: 1,4-benzenedicarboxylate (BDC), 1,3,5-benzenetricarboxylate (BTC), and 2,6-naphthalenedicarboxylate (NDC). These ligands can form a bond with certain metals to form well-ordered, crystalline MOFs [6]. Examples of some of the most common carboxylate-containing MOFs include $\mathrm{Zn}_{4} \mathrm{O}(\mathrm{BDC})_{3}$ also known as MOF-5. This material is considered to be one of the best hydrogen storage materials [7,8]. $\mathrm{Zn}_{4} \mathrm{O}(\mathrm{NDC})_{3}$ known as IRMOF-8 is also a good prospect for hydrogen storage [9-11]. $\mathrm{Cu}_{3}(\mathrm{BTC})_{2}$, also known as HKUST-1, was one of the first MOFs shown to bind hydrogen at metal sites at low temperatures [12]. It has also been shown to be a good prospect for hydrogen storage $[13,14]$. Some other interesting MOFs with carboxylate linkers include CUK-1 and CUK-2 [15], in which CUK = Cambridge University - KRICT. CUK-1 has the formula: $\left[\mathrm{Co}_{3}(2,4-\mathrm{pdc})_{2}\left(\mu_{3}-\mathrm{OH}\right)_{2}\right] 9 \mathrm{H}_{2} \mathrm{O}$ whereas CUK-2 has the formula: $\left[\mathrm{Co}_{2}(6-\mathrm{mna})_{2}\right] 3 \mathrm{H}_{2} \mathrm{O}$. Both of these are 
porous cobalt (II) MOFs which have carboxylate containing linkers. Another interesting material is TUDMOF-1 [16], where TUDMOF-1 = Technical University of Dresden metal organic framework No. 1. This is a porous MOF whose formula is $\mathrm{Mo}_{3}(\mathrm{BTC})_{2}$. There is also a whole series of MOFs that belong to the PCN (Porous Coordinate Network) series [17-19]. These are all carboxylate-based MOFs in which PCN-10, PCN-11, PCN-12 and PCN-12' contain Cu metal sites. PCN-17 is another member of the series but it contains a $\mathrm{Yb}$ metal center. Another interesting carboxylate containing MOF is IRMOF-18 [20]. This is an isorecticular MOF that contains a Zn metal center. UMCM-150 [21] termed University of Michigan crystalline material is a carboxylate based MOF that contains both a binuclear $\mathrm{Cu}(\mathrm{II})$ paddlewheel cluster and a trinuclear $\mathrm{Cu}$ (II) cluster. It shows relatively high excess gravimetric and volumetric $\mathrm{H}_{2}$ uptake. $\mathrm{Cu}-$ BTT [22] contains a BTT (1,3,5-benzenetristetrazolate) linker and a $\mathrm{Cu}$ metal center. As with other $\mathrm{Cu}$ containing MOFs, it has a high density of expose metal sites @ the surfaces. MOF-74 [23] is yet another carboxylate based MOF with a Zn metal center. It has been found to bind hydrogen very well in the low pressure region. The linkers and metal clusters contained in all of the MOFs mentioned here have been tabulated in the supplementary materials Table S1.

It is well known that physisorption correlates with surface area and that greater gas uptake is favored by higher surface area [5]. However, it is also known that the way in which hydrogen interacts with the surfaces (binding energy) may also affect adsorption [24-26]. The interaction of hydrogen with the surface may be affected by factors such as the nature of metal sites, nature of the linkers, etc. [6]. Since surface area may or may not correlate well with adsorption capacity in MOFs containing different types of linkers and/or metal sites, the aim of this work was to determine if other parameters might correlate well with weight percent in those instances.

\subsection{Experimental Procedures}

The following five MOFs were prepared of purchased for this work: $\mathrm{Zn}_{4} \mathrm{O}(\mathrm{BDC})_{3}, \mathrm{Zn}_{4} \mathrm{O}(\mathrm{NDC})_{3}$ $\mathrm{Cu}_{3}(\mathrm{BTC})_{2} \mathrm{Fe}_{3}(\mathrm{BTC})_{2}$ and $\mathrm{Zn}$-Mim (where Mim is 2-Methylimidazole). The $\mathrm{Zn}_{4} \mathrm{O}(\mathrm{BDC})_{3}$ and $\mathrm{Zn}_{4} \mathrm{O}(\mathrm{NDC})_{3}$ were prepared by a rapid solvothermal process developed by Orefuwa et al $[10,11]$. For the $\mathrm{Zn}_{4} \mathrm{O}(\mathrm{BDC})_{3}$ synthesis, $1.89 \mathrm{~g}$ of zinc nitrate hexahydrate $\left(\mathrm{Zn}\left(\mathrm{NO}_{3}\right)_{2} \cdot 6 \mathrm{H}_{2} \mathrm{O}\right)$ was reacted with $0.33 \mathrm{~g}$ of terephtalic acid $\left(\mathrm{H}_{2} \mathrm{BDC}\right)$, and mixed into a solution with $40 \mathrm{ml}$ of anhydrous $\mathrm{N}, \mathrm{N}$-Dimethylformamide, $99.8 \%$ bought from Sigma-Aldrich. Reactants were heated at $443 \mathrm{~K}$ for $2 \mathrm{hrs}$. The product was filtered and purified three (3) times with $5 \mathrm{ml}$ of anhydrous chloroform containing amylenes as stabilizer $\geq 99 \%$, also obtained for SigmaAldrich, and put under vacuum overnight. The product was further degassed at $523 \mathrm{~K}$ for $10 \mathrm{hrs}$. and the BET and Langmiur surface areas were obtained using nitrogen adsorption. The procedure used to prepare $\mathrm{Zn}_{4} \mathrm{O}(\mathrm{NDC})_{3}$ is given in detail elsewhere [10]. The $\mathrm{Cu}_{3}(\mathrm{BTC})_{2}$ was prepared by a mechanochemical synthesis method described in detail by Yang et al [14]. The $\mathrm{Fe}_{3}(\mathrm{BTC})_{2}$ and $\mathrm{Zn}$-Mim were obtained 
commercially from Sigma Aldrich U.S.A. BET surface areas and pore volumes were determined for all the MOFs using a Micromeritics ASAP 2020 sorptometer. Low and high pressure $\mathrm{H}_{2}$ adsorption capacities were determined using the Micromeritics ASAP 2020 sorptometer and a High Pressure Volumetric Analyzer (HPVA-100).

\subsection{Results and Discussion}

In addition to the five MOFs that were prepared or purchased for this work, data for 12 others were obtained from the literature. These MOFs contain a variety of linkers and metal clusters. With the additional data from the literature, it should be possible to make meaningful comparisons among the MOFs to determine what correlations exist in their properties. It is of particular interest to determine what effect factors such as the nature of the linkers and metal clusters may have on the hydrogen adsorption capacities of these MOFs.

\subsection{Surface Areas and Pore Volume}

Surface areas and pore volumes were determined volumetrically from $\mathrm{N}_{2}$ adsorption-desorption isotherms at $77 \mathrm{~K}$, for the five MOFs that were prepared or purchased for this work. Figure 1 contains BET isotherms that were used to calculate surface areas and pore volumes for these MOFs. The values are listed in Table 1 along with data for the 12 additional MOFs that were obtained from the literature. There is a wide range of surface areas from a high of 2300 for UMCM-150 to a low of $420 \mathrm{~m}^{2} \mathrm{~g}^{-1}$ for CUK-2. As expected, the MOFs with high surface areas also have high pore volumes. There does not seem to be any relationship between linker size and surface area. For example, MOF-5 has just one benzene ring in its linker and it has a relatively high surface area of $2163 \mathrm{~m}^{2} \mathrm{~g}^{-1}$ whereas CuK-1 and CuK-2 also have one benzene ring with relatively low surface areas. PCN-17 has a relatively large linker with 4 benzene rings but it has a surface area of only $820 \mathrm{~m}^{2} \mathrm{~g}^{-1}$. There also does not seem to be a relationship between the nature of the metal cluster and surface area. For example, the $\mathrm{Zn}$-containing MOFs have surface areas ranging from 2163 to $783 \mathrm{~m}^{2} \mathrm{~g}^{-1}$.

\subsection{Adsorption Isotherms}

An effort was also made to examine the hydrogen adsorption behavior of the various MOFs at $77 \mathrm{~K}$. Figure 2 contains adsorption isotherms for the five MOFs prepared of purchased for this study. For each isotherm, the weight percentage of hydrogen adsorbed at a pressure of 1 atmosphere was determined. The results are given in Table 1 along with data for the $12 \mathrm{MOFs}$ that were selected from the literature.

It is apparent that the MOFs have a wide range of adsorption capacities ranging from a high of 3.05 wt $\%$ for PCN-12 to a low of $0.88 \mathrm{wt} \%$ for IRMOF-18 at $77 \mathrm{~K}$ and 1 bar. A plot of wt $\%$ versus surface area was made in order to determine if any correlation exists between these two parameters. The plot is shown in 
Figure 3a. The plot shows that a correlation exists but that there is a fairly large amount of scatter in the data points. A correlation coefficient $\left(\mathrm{R}^{2}\right)$ was used to represent the degree of scatter in the data points. A value of $R^{2}=1$ would represent perfect correlation whereas $R^{2}=0$ would represent no correlation. In this case $R^{2}$ was 0.5388 . A possible reason for the relatively low correlation coefficient may be the fact that the surfaces in these MOFs are not uniform. They contain a variety of different linkers, metal sites and structures. The different affinities of hydrogen for each of these surfaces may be responsible for the scatter.

\subsection{Sticking Efficiency}

It was mentioned earlier that the way in which hydrogen interacts with the surfaces (binding energy) may also affect adsorption [24-26]. Therefore a new parameter denoted the sticking factor $(\Theta)$ was developed with the hope that it would correlate better with the wt $\%$ hydrogen adsorbed than surface area. The sticking factor (defined as the percent gas adsorbed per $\mathrm{m}^{2}$ of surface area per gram of material) was calculated for each gas based on the following equation:

$$
\theta=\frac{Q_{a d s}}{S_{S A}} \times \frac{N_{A}}{M_{m m}}
$$

Where $Q_{\text {ads }}$ is the weight percentage of gas adsorbed, $S_{\mathrm{SA}}$ is the surface area of the MOF in $\mathrm{m}^{2} / \mathrm{g}, \mathrm{N}_{\mathrm{A}}$ is Advogadro's number and $\mathrm{M}_{\mathrm{mm}}$ is the molar mass of the adsorbed gas. Since the sticking factor is the percentage of hydrogen gas adsorbed per unit area of surface, it actually represents the efficiency in which the molecules are able to bind to the surface. If a material has a large surface area but, due to the nature of the binding sites, has low sticking efficiency, then it is possible that it will adsorb a relatively small amount of hydrogen.

The sticking factors calculated from Equation 1 are given in Table 1 for all of the MOFs included in this work. Figure $3 \mathrm{~b}$ contains a plot of sticking factor versus the weight percentage of hydrogen on the surface. The results show that there is a reasonably good correlation, with $\mathrm{R}^{2}=0.7486$. This is significantly better than the 0.5388 that was obtained when surface area was plotted versus wt $\%$ using the same set of MOFs. However, as noted earlier, these MOFs contain a variety of different metal sites and organic linkers. Since the surfaces of these MOFs would be expected to be different it might be better to examine correlations between surface area and wt $\%$ on MOFs containing similar surfaces. Since five of the MOFs (PCN-10, PCN-11, PCN-12, PCN-12', and PCN-17) belong to the PCN (Porous Coordination Network) family of MOFs their surfaces should have similar properties. Therefore it was decided to construct plots of $\mathrm{wt} \%$ versus surface area and wt\% versus sticking factor using only these five MOFs. The figures for these are given in the supplementary materials (Figures S1a and S2b). Direct correlations were found in both plots. However, the plot of wt\% versus surface area had a significantly better correlation $\left(R^{2}=0.8974\right)$ than the plot of wt\% versus sticking efficiency $\left(\mathrm{R}^{2}=0.5462\right)$. This demonstrated that, in order to make 
comparisons between surface area and wt\% among MOFs, they must have similar surface features. It was also apparent that three of the MOFs (Cu-BTC, Fe-BTC and TUDMOF-1) contained the same BTC linker but different metals ( $\mathrm{Cu}, \mathrm{Fe}$ and Mo, resp.). Therefore plots of wt\% versus surface area and sticking factor were constructed to make similar comparisons. These plots are given in the supplementary materials (Figures S2a and S2b). Both plots displayed nearly identical correlation coefficients that were both excellent. The plot of wt\% versus surface area had a slightly better correlation $\left(R^{2}=0.9901\right)$ than the plot of wt\% versus sticking efficiency $\left(\mathrm{R}^{2}=0.9862\right)$. It is thus evident that both surface area and sticking efficiency correlate well with wt\% when the surfaces have similar characteristics (ie. similar linkers).

It was also of interest to determine how well wt\% would correlate with surface area and sticking efficiency in a series of MOFs containing the same metal site but different linkers. Since five of the MOFs contain a $\mathrm{Zn}$ metal center but different linkers they were chosen for the comparison. They are $\left(\mathrm{Zn}_{4} \mathrm{O}(\mathrm{BDC})_{3}\right.$, $\mathrm{Zn}_{4} \mathrm{O}(\mathrm{NDC})_{3}$ IRMOF-18, MOF-74 and $\left.\mathrm{Zn}-\mathrm{Mim}\right)$. The plots of wt $\%$ versus surface area and sticking factor are shown in Figures S3a and S3b. It was found that the plot of wt\% versus surface area showed almost no correlation with $\mathrm{R}^{2}=0.1016$ whereas the plot of $\mathrm{wt} \%$ versus sticking factor had $\mathrm{R}^{2}=0.5064$. In this series the MOFs contained dissimilar linkers ranging from dicarboxylate and tricarboxylate to methyl imidazole. The poor correlation coefficient demonstrates the importance of having similar linkers when comparing the $\mathrm{H}_{2}$ gas adsorption capacities of MOFs to surface areas. It is also interesting to note that when sticking factors are used apparently this is not as necessary. Sticking factors are related to the binding energy and therefore comparisons of gas adsorption on different MOFs can be made regardless of the surface make-up. This explains why the graph of wt\% versus surface area in Figures 3a, containing MOFs with many different linkers, did not give as good a correlation as the one with wt $\%$ versus sticking factor in Figure $3 b$.

It is also interesting to note that seven of the MOFs contain $\mathrm{Cu}$ metal sites. These $\mathrm{Cu}$ sites are a bit different than those for many other metals. It has been reported that, in many cases, metal centers are fully coordinated and shielded from their surrounding environment. Thus they have little impact on adsorption. However, the $\mathrm{Cu}$ metal clusters are not fully coordinated to the organic ligands. This leads to coordinative unsaturated sites, which are also termed "open metal sites" [6]. If one compares the sticking factors and hydrogen adsorption capacities of the $\mathrm{Cu}$-containing MOFs with others in Figures $3 \mathrm{a}$ and $3 \mathrm{~b}$ it is apparent the $\mathrm{Cu}$-containing MOFs are generally clustered at the high end of the graph. This indicates that they have higher sticking factors and higher adsorption capacities than the other MOFs. The most likely reason for this is that $\mathrm{Cu}$ is able to more effectively bind hydrogen due to the open metal sites. 


\subsection{Enthalpy of Adsorption}

Sticking efficiency has been found to correlate well with adsorption capacity. Since sticking efficiency is related to the ability of hydrogen to stick onto the surface of MOFs, it seemed likely that the strength of physisorption (binding energy) on some gas surfaces may be greater than others. If this is the case, enthalpies of hydrogen adsorption for each MOF should reflect these diffenences. Therefore adsorption enthalpies were obtained by applying the van't Hoff equation:

$$
\ln P_{1}-\ln P_{2}=-\frac{\Delta \mathrm{H}}{R}\left(\frac{1}{T_{1}}-\frac{1}{T_{2}}\right)
$$

Where $\Delta \mathrm{H}$ is the isosteric heat of adsorption $(\mathrm{kJ} / \mathrm{mol}), \mathrm{T}_{1}$ and $\mathrm{T}_{2}$ are Kelvin temperatures, $\mathrm{P}_{1}$ and $\mathrm{P}_{2}$ are adsorbate pressures in (bar) and $\mathrm{R}$ is the universal gas constant. For each of the MOFs that were prepared or purchased for this work, the adsorption pressure was obtained at two temperatures and the adsorption enthalpy was obtained from Equation 2. The adsorption enthalpies are given in Table 1 along with those reported in the literature for some of the other MOFs. An attempt was made to determine if a correlation exists between sticking factor and heat of adsorption. From the plot of the isosteric heats of adsorption versus sticking factors in Figure 4 it can be seen that a good correlation does exist $\left(R^{2}=0.7068\right)$. This demonstrates that the sticking factor is directly related to the strength of adsorption of the sorbate molecule on the surface. Since a correlation was also found between sticking factor and the quantity of hydrogen adsorbed, this confirms that the amount of hydrogen adsorbed on a MOF is related to both the strength of adsorption of the sorbate molecule on the surface as well as the surface area of the MOF.

\subsection{Conclusion}

In this work, a comparison of the hydrogen adsorption capacities of 17 MOFs was made. Results showed that a better correlation exists between sticking efficiency and hydrogen adsorption capacity than between surface area and adsorption capacity. However, when only MOFs containing similar types of linkers were included in the comparison, the surface area correlated somewhat better with adsorption capacity than did sticking efficiency. This demonstrate that sticking efficiency correlates with adsorption capacity for a broader range of dissimilar MOFs than does surface area. It was also found that MOFs with open metal sites generally have larger sticking efficiencies and greater $\mathrm{H}_{2}$ holding capacities than those that don't. Since sticking efficiencies were shown to be proportional to adsorption enthalpy, this demonstrates that sticking efficiency is a direct measure of the strength of hydrogen interaction with the surface. 


\begin{tabular}{|c|c|c|c|c|c|c|c|c|}
\hline MOFs & Metal & $\begin{array}{l}\text { Organic } \\
\text { Linker }\end{array}$ & $\begin{array}{l}\text { Surface } \\
\text { Area } \\
\left(\mathrm{m}^{2} \mathrm{~g}^{-1}\right)\end{array}$ & $\begin{array}{l}\text { Pore } \\
\text { Volume } \\
\left(\mathrm{cm}^{3} \mathrm{~g}^{-1}\right)\end{array}$ & $\begin{array}{l}\mathrm{H}_{2} / 77 \mathrm{~K} \\
\text { / } 1 \text { bar } \\
\text { (wt.\%) }\end{array}$ & $\begin{array}{l}\text { Sticking } \\
\text { Efficiency } \\
\left(\times 10^{20}\right)\end{array}$ & $\begin{array}{l}\Delta \mathrm{H} \\
\left(\mathrm{kJmol}^{-1}\right)\end{array}$ & Ref. \\
\hline $\mathrm{Zn}_{4} \mathrm{O}(\mathrm{BDC})_{3}$ & $\mathrm{Zn}$ & $\mathrm{H}_{2} \mathrm{bdc}$ & 2163 & 0.87 & 1.40 & 1.94 & $5.8 \pm 0.4$ & This work \\
\hline $\mathrm{Zn}_{4} \mathrm{O}(\mathrm{NDC})_{3}$ & $\mathrm{Zn}$ & $\mathrm{H}_{2} \mathrm{ndc}$ & 1599 & 0.63 & 1.74 & 3.24 & $6.0 \pm 0.5$ & This work \\
\hline Zn-Mim & $\mathrm{Zn}$ & 2-mim & 1581 & 0.64 & 1.26 & 2.38 & $5.4 \pm 1.0$ & This work \\
\hline $\mathrm{Cu}_{3}(\mathrm{BTC})_{2}$ & $\mathrm{Cu}$ & $1,3,5$-btc & 1398 & 0.58 & 2.00 & 4.27 & $7.3 \pm 0.4$ & This work \\
\hline $\mathrm{Fe}_{3}(\mathrm{BTC})_{2}$ & $\mathrm{Fe}$ & $1,3,5$-btc & 1031 & 0.43 & 0.89 & 2.58 & $5.4 \pm 1.1$ & This work \\
\hline CUK-1 & Co & 2,4-pdc & 630 & 0.26 & 1.60 & 1.23 & - & 15 \\
\hline CUK-2 & Co & 6-mna & 420 & 0.17 & 0.66 & 1.21 & - & 15 \\
\hline TUDMOF-1 & Mo & $1,3,5-b t c$ & 1280 & 0.67 & 1.75 & 4.08 & - & 16 \\
\hline PCN-10 & $\mathrm{Cu}$ & $\mathrm{H}_{4}$ aobtc & 1407 & 0.67 & 2.34 & 4.96 & - & 17 \\
\hline PCN-11 & $\mathrm{Cu}$ & $\mathrm{H}_{4} \mathrm{sbtc}$ & 1931 & 0.91 & 2.55 & 3.94 & 19.1 & 17 \\
\hline PCN-12 & $\mathrm{Cu}$ & $\mathrm{H}_{4}$ mdip & 1943 & 0.94 & 3.05 & 4.68 & - & 18 \\
\hline PCN-12' & $\mathrm{Cu}$ & $\mathrm{H}_{4}$ mdip & 1577 & 0.73 & 2.4 & 4.54 & - & 18 \\
\hline PCN-17 & $\mathrm{Yb}$ & $\mathrm{H}_{3}$ tatb & 820 & 0.34 & 0.94 & 3.42 & - & 19 \\
\hline IRMOF-18 & $\mathrm{Zn}$ & tmbdc & 1501 & - & 0.88 & 1.75 & - & 20 \\
\hline UMCM-150 & $\mathrm{Cu}$ & $\mathrm{H}_{3} \mathrm{bptc}$ & 2300 & 1 & 2.1 & 2.72 & 7.3 & 21 \\
\hline Cu-BTT & $\mathrm{Cu}$ & $\mathrm{H}_{3} \mathrm{btt}$ & 1710 & - & 2.42 & 4.22 & - & 22 \\
\hline MOF-74 & $\mathrm{Zn}$ & dhtp & 783 & 0.39 & 1.75 & 6.66 & 8.3 & 23 \\
\hline
\end{tabular}

\section{Acknowledgement}

This research was financially supported by the U.S. Department of Energy Award Number DE-FC3606GO86046 and the U.S. Department of Transportation Assistance Number DTOS59-07-G-00056.

\section{Figure Captions}

Figure 1. BET isotherms for various MOFs at $77 \mathrm{~K}$. 
Figure 2. Hydrogen adsorption isotherms of various MOFs at $77 \mathrm{~K}$.

Figure 3a. Weight percent hydrogen adsorbed at $77 \mathrm{~K}$ versus surface area.

Figure 3b. Weight percent hydrogen adsorbed at $77 \mathrm{~K}$ versus sticking factor.

Figure 4. Adsorption enthalpy versus sticking factor.

\section{Table Caption}

Table 1. Hydrogen Adsorption Analysis Data @ 77 K

\section{References}

[1] O.M. Yaghi, M. O’Keeffe, N.W. Ockwig, H.K. Chae, M. Eddaoudi, J. Kim, Nature 423 (2003) 705714.

[2] S. Kitagawa, R. Kitaura, and S.-I. Noro, Angew. Chem. Int. Ed. 43 (2004) 2334-2375.

[3] D. Zhao, D. Yuan and H.-C. Zhou, Energy Environ. Sci., 1 (2008) 222-235.

[4] M.P. Suh, H.J. Park, T.K. Prasad and D-W Lim, Chem. Rev. 112 (2012) 782-835.

[5] L. Murray, M. Dinca and J.R. Long, Chem. Soc. Rev. 38 (2009) 1294-1314.

[6] P. Llewellyn, G. Maurin and J. Rouquerol, Adsorption by Metal Organic Frameworks, in F. Rouquerol, J. Rouquerol, K.S.W. Sing, P. Llewellyn and G. Maurin (Eds), Adsorption by Powders and Porous Solids; Principles, Methodology and Applications, Second Ed., Academic Press, 2014 pp. 565-610.

[7] J.L.C. Rosewell, A.R. Millward, K.S. Park and O.M. Yaghi, J. Am. Chem. Soc., 126 (2004) 56665667.

[8] N. L. Rosi, J. Eckert, M. Eddaoudi, D. T. Vodak, J. Kim, M. O’Keefe, O. M. Yaghi, Science, 300 (2003) 1127-1129.

[9] A. Dailly, J. J. Vajo and C. C. Ahn, J. Phys. Chem. B, 110 (2006) 1099-1101.

[10] S. Orefuwa, H. Yang, and A. Goudy, Micropor. Mesopor. Mater., 153 (2012) 88-93.

[11] S. Orefuwa, E. Iriowen, H. Yang, B. Wakefield, A. Goudy, Micropor. Mesorpor. Mater. 177 (2013) 82- 90.

[12] V. K. Peterson, Y. Liu, C. M. Brown and C. J. Kepert, J. Am. Chem. Soc., 128 (2006) 15578-15579.

[13] B. Xiao, P. S. Wheatley, X. Zhao, A. J. Fletcher, S. Fox, A. G. Rossi, I. L. Megson, S. Bordiga, L. Regli, K. M. Thomas, and R. E. Morris, J. Am. Chem. Soc., 129 (2007) 1203-1209.

[14] H. Yang, S. Orefuwa, A. Goudy. Micropor. Mesorpor. Mater. 143 (2011) 37- 45.

[15] S.M. Humphrey, J.-S. Chang, S. H. Jhung, J.W. Yoon, and P.T. Wood, Angew. Chem. Int. Ed. 46 (2007) 272-275. 
[16] M. Kramer, U. Schwarz, and S. Kaskel, J. Mater. Chem., 16 (2006) 2245-2248.

[17] X.-S. Wang, S. Ma, K. Rauch, J.M. Simmons, D. Yuan, X. Wang, T. Yildirim, W.C. Cole, J.J. Lopez, A. Meijere and H.-C. Zhou, Chem. Mater. 20 (2008) 3145-3152.

[18] X.-S. Wang, S. Ma, P.M. Forster, D. Yuan, J. Eckert, J.J. Lopez, B.J. Murphy, J.B. Parise, and H.-C. Zhou, Angew. Chem. Int. Ed. 47 (2008) 7263-7266.

[19] S. Ma, X.-S. Wang, D. Yuan, and H.-C. Zhou, Angew. Chem. Int. Ed. 47 (2008) 4130-4133.

[20] J.L.C. Rowsell, A.R. Millward, K.S. Park and O.M. Yaghi, J. Am. Chem. Soc. 126 (2004) 5666-5667.

[21] A.G. Wong-Foy, O. Lebel and A.J. Matzger, J. Am. Chem. Soc. 129 (2007) 15740-15741.

[22] M. Dinca, W.S. Han, Y. Liu, A. Dailly, C.M. Brown and J.R. Long, Angew. Chem. Int. Ed. 46 (2007) 1419-1422.

[23] J.L.C. Rowsell, and O.M. Yaghi, J. Am. Chem. Soc. 128 (2006) 1304-1315.

[24] P. Srepusharawoot, C.M. Araujo, A. Blomqvist, R.H. Scheicher and R. Ahuja, J. Chem. Phys. 129 (2008) 164104

[25] T. Adit and S. Pal, Int. J. Hydrogen Energy, 35 (2010) 12846-12857

[26] N. Nijem, L. Kong, Y. Zhao, H. Wu, J. Li, D.C. Langreth and Y.J. Chabal, J. Am. Chem. Soc. 133 (2011) 4782-4784. 


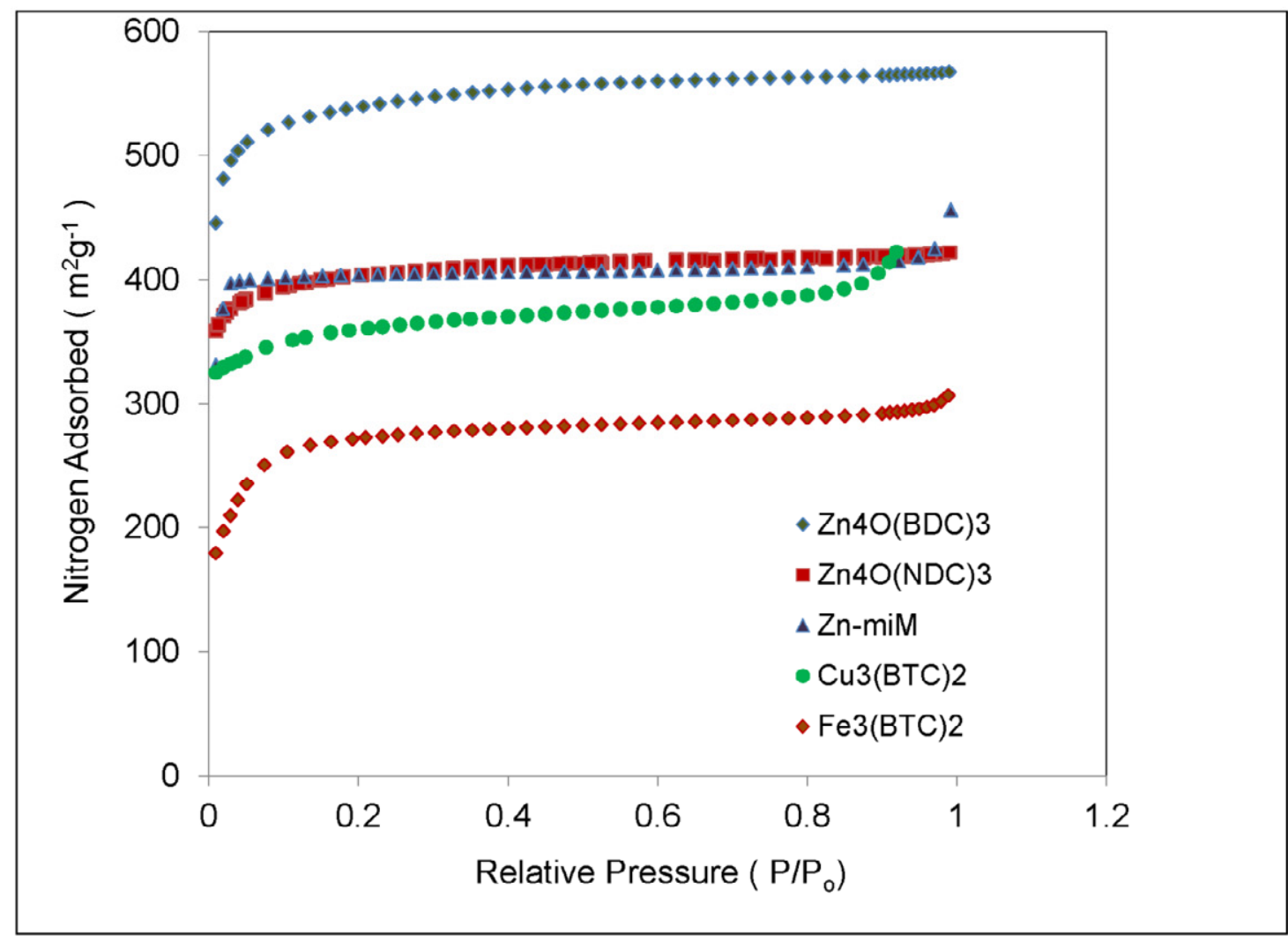




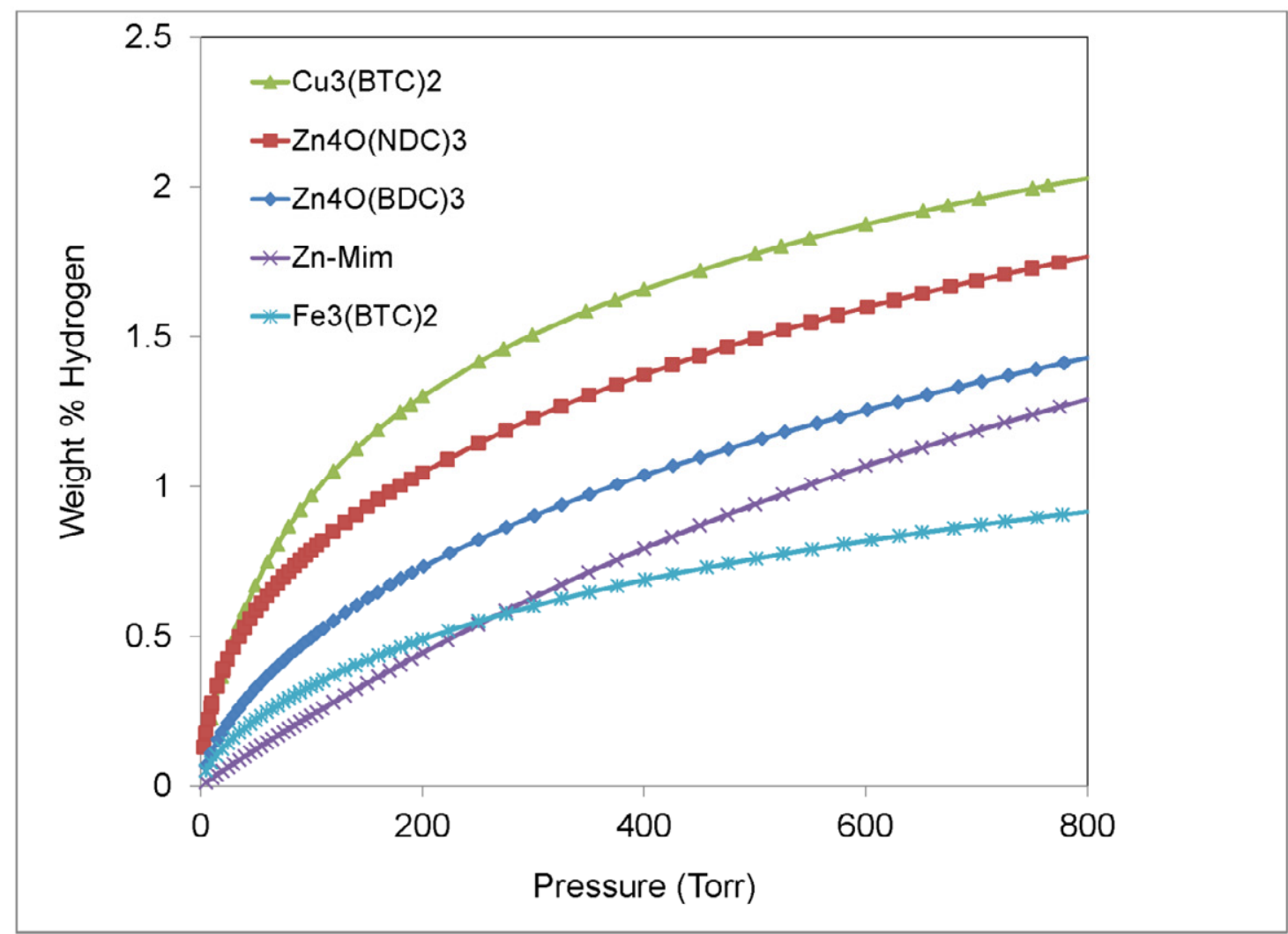




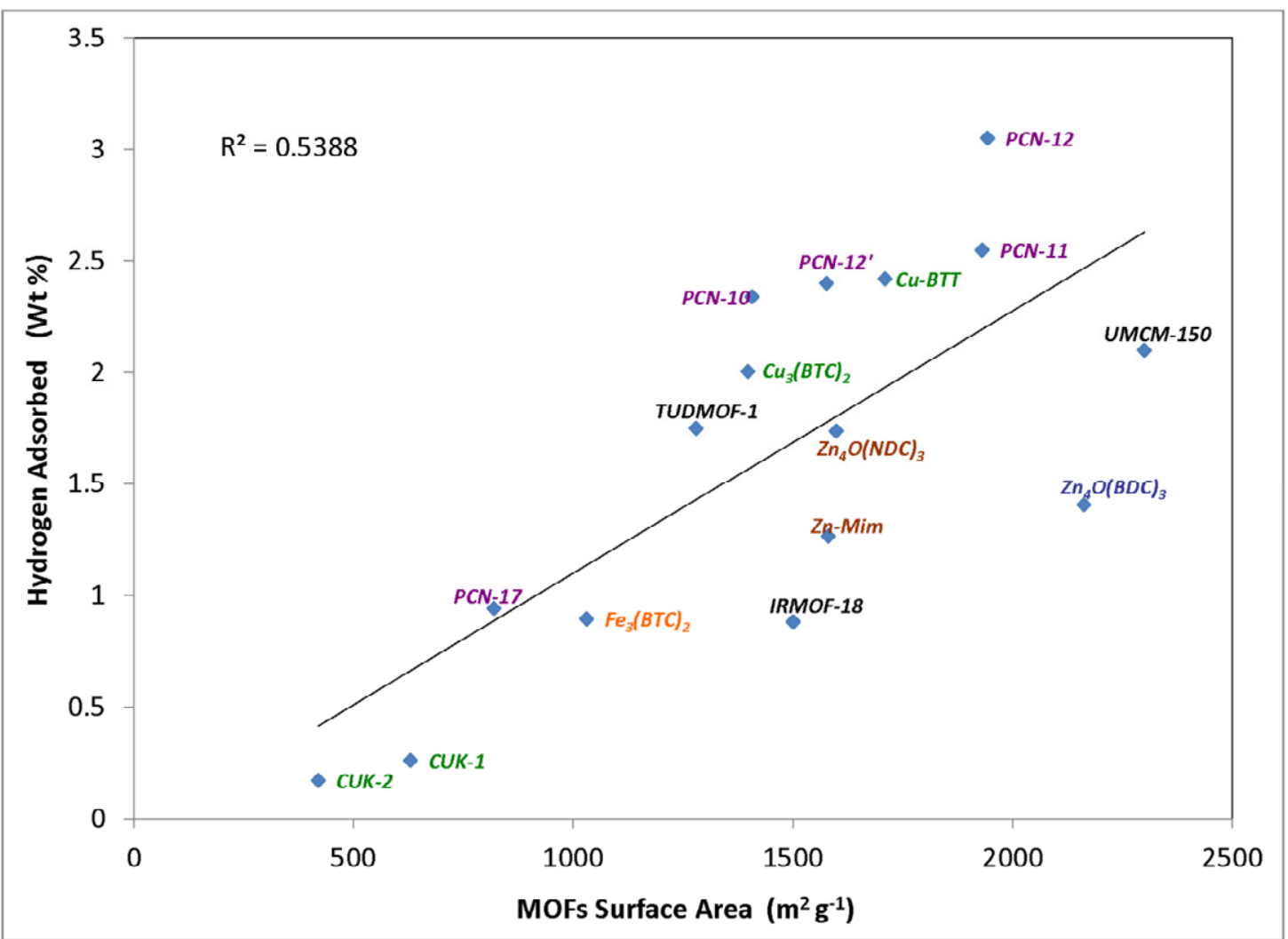




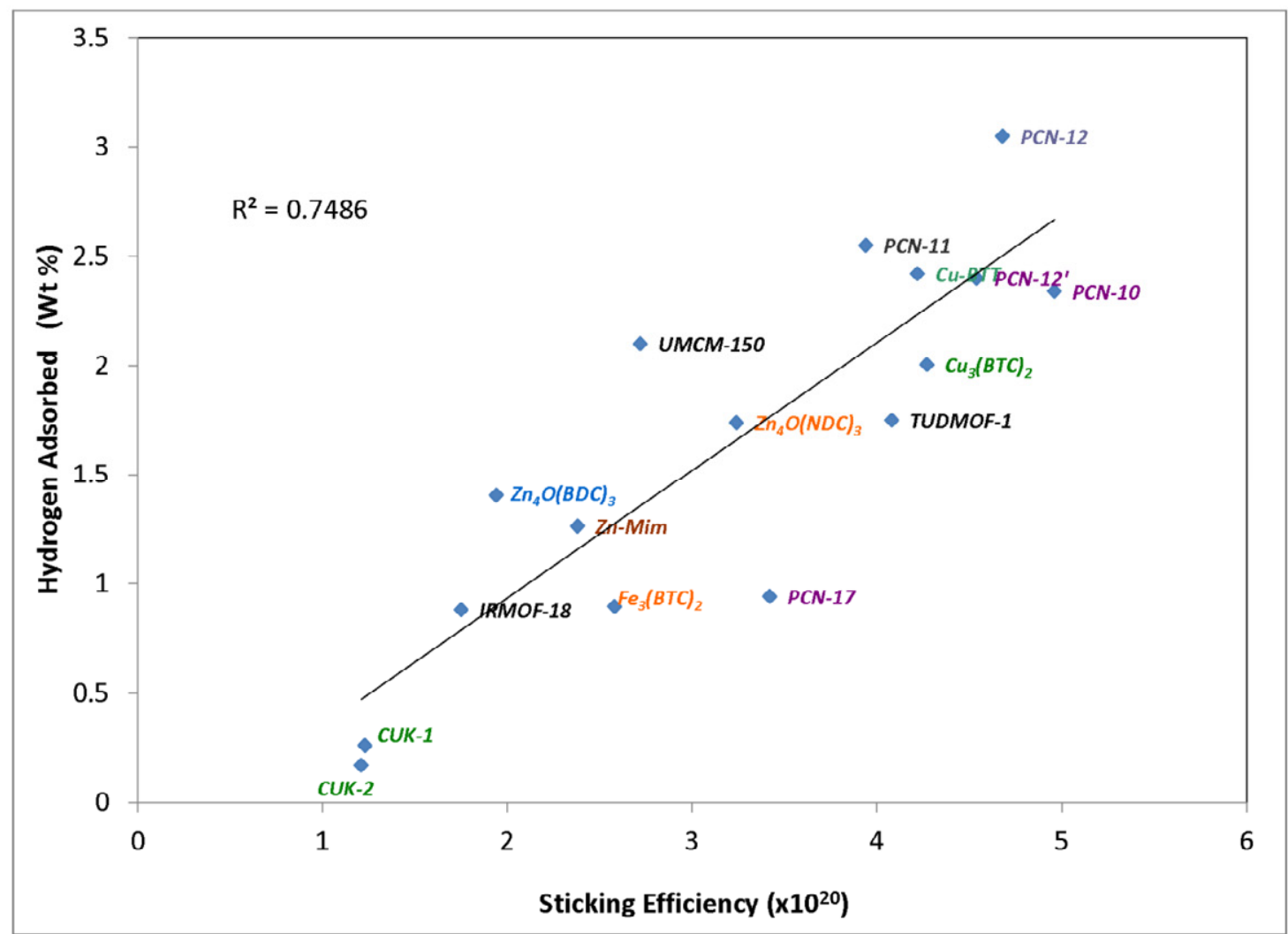


Graphical Abstract

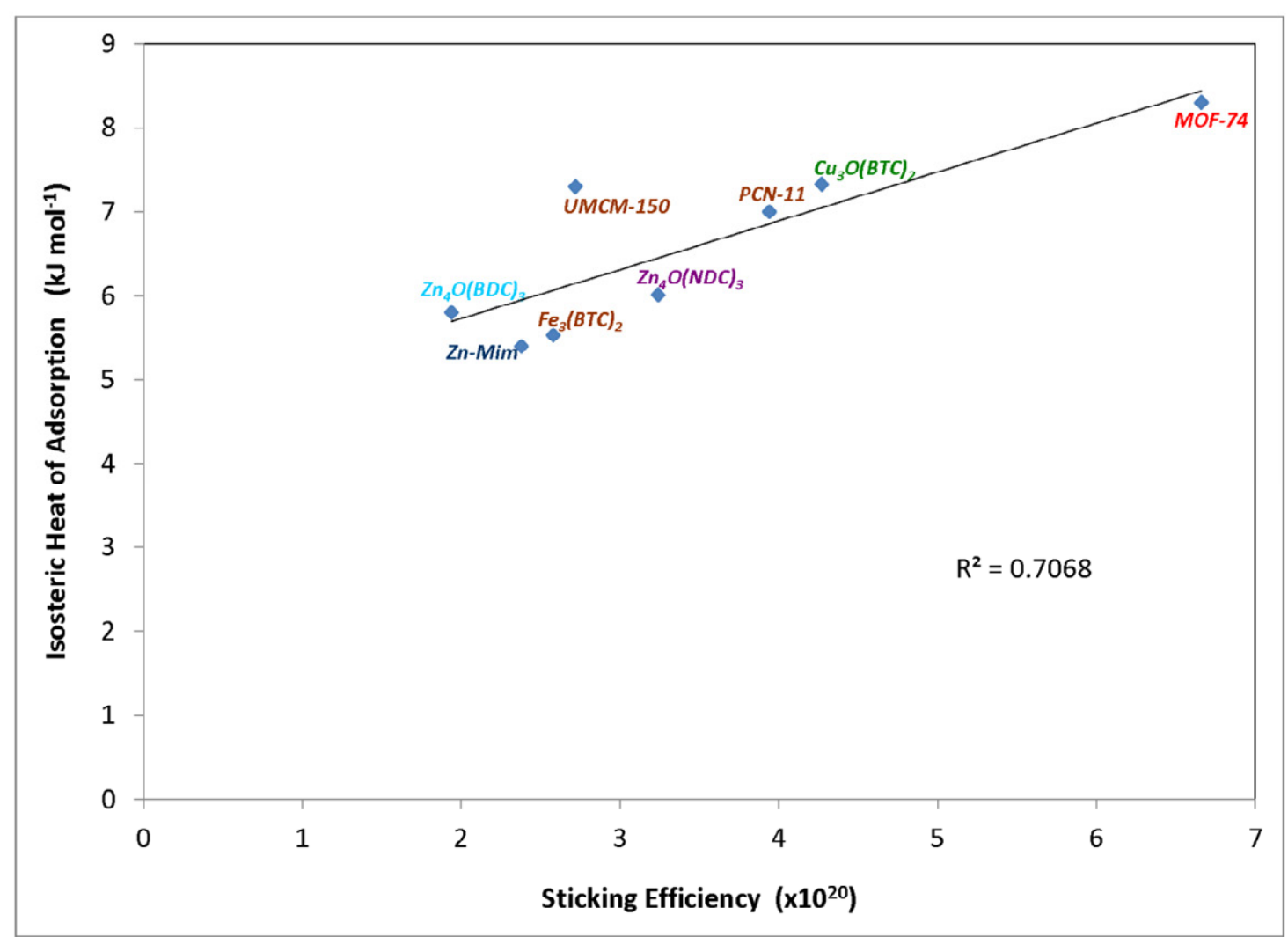

